\title{
Education for Communities in Dealing with People with Mental Disorders in the Context of Community Peace in Abiansemal Village, Badung Regency
}

\author{
Komang Ema Marsitadewi, Ni Made Anggriyani, I Wayan Sudemen \\ \{emarsitadewi@gmail.com; nimadeanggriyani@gmail.com; iwayansudemen@yahoo.co.id\} \\ Warmadewa University, Bali, Indonesia
}

\begin{abstract}
Mental disorders are manifestations of behavioral deviations due to emotional distortion. It is also defined as the irregularities in behavior, which occurs due to the decline in all psychiatric functions. Therefore, the existence of these deviations caused People with Mental Disorders (ODGJ) to be treated differently, and are often called crazy. One form of treatment inequality that leads to wrong actions in dealing with ODGJ is the shackling practice. Data obtained from the Indonesian Ministry of Health in 2013, showed that $1.7 \%$ out of 1,000 Indonesians have experienced schizophernia or psychosis, while approximately $14.8 \%$ had been shackled in their lives using ODGJ. The large number of ODGJs in Bali Province shows that there is a need for appropriate handling from both the government and the community. The problem faced by the family ODGJ people includes economical and social factors. Stigma in the community of people with mental disorders also complicates the comprehensive handling process. Goffman in Lestari stated that stigma on people with mental disorders has two main components. Based on these problems, a community service is conducted to provide education related to the handling of ODGJ. It automatically helps to eliminate stigma in the community and helps families with ODGJ members in handling them independently.
\end{abstract}

Keywords: People With Mental Disorders (ODGJ), Handling Education and Training, Community Peace.

\section{Pendahuluan}

Orang gila merupakan kalimat yang paling sering terucap ketika melihat atau mengetahui orang yang mengalami gangguan jiwa atau saat ini disebut dengan orang dengan gangguan jiwa (ODGJ). Orang dengan gangguan jiwa (ODGJ) adalah istilah resmi bagi penyandang gangguan jiwa berdasarkan Undang-Undang Nomor 18 Tahun 2014 tentang Kesehatan Jiwa. Sehingga penyebutan orang gila tidak dibenarkan lagi berdasarkan hukum yang ada di Indonesia. Namun akibat minimnya pengetahuan masyarakat akan hal tersebut menyebabkan penyebutan orang yang mengalami gangguan jiwa masih lebih akrab dipanggil dengan orang gila oleh masyarakat. Di Indonesia, berdasarkan hasil survey kesehatan tahun 2013 terdapat 1.7 per 1000 penduduk Indonesia yang menderita skizofrenia atau psikosis. Dimana artinya bahwa dari 1000 penduduk Indonesia diantaranya terdapat sebesar 1.7 mengalami skizofrenia 
atau psikosis dan juga artinya bahwa masih ada kesempatan 1.7 dari 1000 penduduk Indonesia tersebut untuk dipanggil orang gila akibat dari minimnya pengetahuan masyarakat. Angka yang cukup besar tersebut sepatutnya disadari oleh pemerintah agar penanganan yang tepat baik dari pemerintah, keluarga dan masyarakat dapat dilakukan. Apalagi melihat keadaan ODGJ di Indonesia sendiri masih banyak mengalami ketimpangan perlakuan. Bukan hanya oleh pemerintah, masyarakat luas, bahkan dari keluarga sendiri.

Gangguan jiwa merupakan manifestasi dari bentuk penyimpangan perilaku akibat adanya distorsi emosi, sehingga ditemukan ketidakwajaran dalam bertingkah laku dan terjadi karena menurunnya semua fungsi kejiwaan. Adanya penyimpangan perlakuan tersebut menyebabkan ODGJ cenderung diperlakukan berbeda, bukan hanya berdasarkan penyebutan ODGJ yang masih kerap dipanggil orang gila. Salah satu bentuk ketimpangan perlakuan bahkan cenderung mengarah pada tindakan yang salah dalam menghadapi ODGJ yakni pemasungan terhadap ODGJ. Berdasarkan data Kementrian Kesehatan Republik Indonesia tahun 2013, diantara para 1.7 dari 1000 penduduk Indonesia yang mengalami skizofernia atau psikosis tersebut, kurang lebih $14,8 \%$ pernah dipasung dalam masa hidupnya. Padahal pemasungan bukan bentuk penangan atau tindakan tepat dalam memperlakukan ODGJ.

Provinsi Bali sendiri menduduki peringakat keempat untuk jumlah penderita gangguan jiwa berat di Indonesia. Dari empat juta warga Bali, sebanyak 0,23 persen merupakan Orang Dengan Gangguan Jiwa (ODGJ). Data dari Dinkes Provinsi Bali, tercatat penderita ODGJ mencapai 4829 orang. Dengan rincian seperti digram dibawah ini.

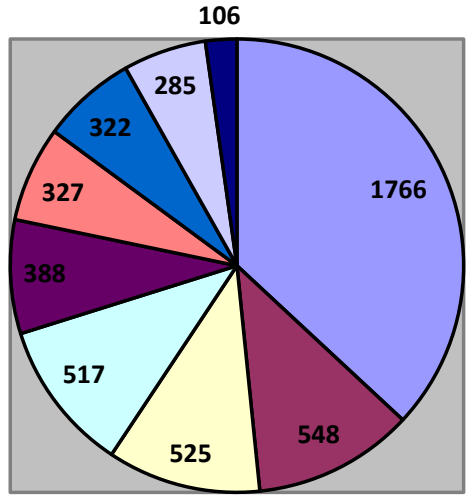

$$
\begin{array}{|l|}
\hline \square \text { Tabanan } \\
\square \text { Klungkung } \\
\square \text { Denpasar } \\
\square \text { Bulelelng } \\
\square \text { Jembrana } \\
\square \text { Badung } \\
\square \text { Bangli } \\
\square \text { Gianyar } \\
\square \text { Karangasem }
\end{array}
$$

Gambar 1. Data ODGJ per Kabupaten/Kota di Provinsi Bali

dilihat dari data diatas, Kabupaten Tabanan menduduki peringkat pertama jumlah ODGJ terbanyak dimProvinsi Bali, yakni sebanyak 1766 orang. Kemudian disusul dengan Kabupaten Klungkung dan Denpasar diurutan kedua dn ketiga. Kabupaten dengan jumlah ODGJ paling sedikit diduduki oleh Kabupaten paling timur di Provinsi Bali yakni Karangasem degan jumlah 106 orang ODGJ.

Melihat cukup banyaknya jumlah penderita ODGJ di Provinsi Bali mengindikasikan bahwa harus ada tindakan penangan yang tepat baik dari pemerintah dan masyarakat. Memiliki keluarga dengan status ODGJ merupakan hal yang berat bagi keluarga. Beban yang ditanggung oleh keluarga yang hidup bersama penderita ODGJ meliputi beberapa faktor, baik secara ekonomi maupun sosial. Stigma di masyarakat terhadap penderita gangguan jiwa juga mempersulit penanganan penderita gangguan jiwa secara komprehensif. Goffman dalam 
Lestari menyatakan bahwa stigma terhadap penderita gangguan jiwa memiliki dua komponen utama, yaitu yang bersifat publik (reaksi umum dari publik terhadap orang yang menderita gangguan jiwa) dan stigma individu (prasangka orang itu sendiri terhadap gangguan jiwa yang diderita yang cenderung kembali kepada dirinya sendiri). Sehingga stigma terhadap penderita gangguan jiwa terutama gangguan jiwa berat masih perlu dikaji lebih mendalam, untuk mencari solusi yang tepat dalam penanganan penderita gangguan jiwa berat di masyarakat, dan lebih luas untuk mendukung program Indonesia Bebas Pasung 2019.

Adanya stigma publik kian menekan adanya penangan yang tepat bagi penderita ODGJ. Stigma ialah sebuah label yang cenderung lebih mengarah terhadap hal negative yang melekat pada tubuh seseorang. Stigma tumbuh dan berkembang dari masyarakat dan dianggap sebagai sesuatu yang benar. Hal inilah yang terjadi pada orang dengan gangguan jiwa (ODGJ). lagi tidak baik dari masyarakat bahkan dari keluarga ODGJ sendiri. Padahal seharusnya sebagai orang terdekat yang memahami ODGJ, keluarga dapat memperlakukan keluarga yang menjadi ODGJ dengan sebaik-baiknya.

\section{Hasil Kegiatan}

Sesuai dengan judul pengabdian Pendidikan Bagi Masyarakat dalam Menghadapi Orang Dengan Gangguan Jiwa (ODGJ) dalam Konteks Ketentraman Bermasyarakat Di Desa Abian Semal, Kabupaten Badung maka pada bab ini, penyusun menguraikan bentuk pemecahan masalah dalam mengahadapi Orang Dengan Gangguan Jiwa (ODGJ)

\subsection{Penjajakan dengan Perbekel dan seluruh staff Desa Abiansemal}

Penjajakan ini dimaksudkan untuk memberikan gambaran umum kegiatan yang akan dilaksakan dalam rangka pemberian sosislaisasi dan pelatihan bagi masyarakat ataupun anggota keluarga yang memiliki anggota keluarga Orang Dengan Gangguan Jiwa (ODGJ). Penjajakan yang dilakukan terhadap Perbekel dan juga staff Desa Abiansemal dilakukan sebanyak dua kali, dengan rincian:

1. 20 Agustus 2019

Pada tanggal 20 Agustus 2019, tim menyampaikan gambaran umum pelaksanaan kegiatan sosialisasi dan pelatihan yang akan diberikan kepada masyarakat atauapun keluarga Orang Dengan Gangguan Jiwa (ODGJ). Pada tanggal 20 Agustus juga turut memastikan kesanggupan Perbekel untuk mengerahkan masyarakat ataupun keluarga dari ODGJ. Karena memang target dari sosialisasi dan pelatihan ini ialaha masyarakat an anggota keluraga ODGJ bukan ODGJ secara langsung.

2. 27 Agustus 2019

Pada tanggal 27 Agustus 2019 yakni penajajakan lanjutan dari penjajakan sebelumnya. Sekaligus memastikan kesiapan ruangan dan segala sarana dan prasarana yang dibutuhkan dalam pelaksanaan kegiatan sosialisiasi pendidikan bagi masyrakat dan juga pelaihan bagi anggota keluarga ODGJ.

\subsection{Pendataan masyarakat Orang Dengan Gangguan Jiwa (ODGJ)}

Pendataan masyarakat Orang Dengan Gangguan Jiwa (ODGJ) untuk mengetahui berapa jumlah ODGJ yang dimiliki oleh Desa Abiansemal. Hal ini guna mempermudah pelaksanaan kegiatan sosialisasi dan pelatihan dalam penanganan ODGJ yang akan dilakukan. Pendataan juga dilakukan untuk membantu Desa Abiansemal memiliki data secara lebih detail tentang 
jenis ODGJ yang dimiliki yang nantinya akan dimasukkan kedalam sistem informasi kependudukan Desa Abiansemal. Dengan adanya update data ini diharapkan target sosialisasi dan pelatihan menjadi tepat sehingga pemberian sosialisasi dan pelatihan dalam penanganan ODGJ dapat memberikan manfaat yang maksimal.

\subsection{Pemberian pendidikan tentang penanganan Orang Dengan Gangguan Jiwa}

Pendidikan tentang penanganan ODGJ diberikan kepada anggota keluarga dan juga masyarakat Desa Abiansema guna memberikan pengetahuna baru bagi anggota keluarga dan juga masyarakat terkait ODGJ. Hal ini dilakukan agar tidak hanya masyarakat yang dapat merasakan kenyamanan tinggal dan bermasyarakat di Desa Abiansemal melainkan juga ODGJ sendiri. Saat ini gangguan jiwa didefinisikan dan ditangani sebagai masalah medis. Gangguan jiwa menurut Depkes RI (2010) adalah suatu perubahan pada fungsi jiwa yang menyebabkan adanya gangguan pada fungsi jiwa yang menimbulkan penderitaan pada individu dan hambatan dalam melaksanakan peran sosial. Pelakasanaan pemberian pendidikan bagi masyarakat dan juga anggota keluarga yang memiliki ODGJ. Pendidikan ini memang tidak hanya dikususkan bagi anggota keluarga melainkan juga masyarakat untuk dapat memberikan manfaat yang lebh luas akan ODGJ. Diskriminasi mulai dari penyebutan, penerimaan hingga perlakuan tidak hanya dilakukan oleh anggota keluarga bahkan masyarakat sekitar. Hal ini yang nantinya akan memperburuk keadaan ODGJ itu sendiri. Dengan adanya pendidikan bagi masyarakat dan juga anggota keluarga tentang ODGJ diharapkan ODGJ sendiri mendapatkan pelakukan yang lebih baik dari seluruh pihak yang berada dilingkungan dimana ODGJ itu sendiri tinggal. Pendidikan yang dilakukan diberikan oleh seorang psikolog sehingga materimateri yang diberikan bersumber langsung dari ahlinya. Kegiatan pemberian pendidikan bagi masyarakat dan juga anggota keluarga tentang ODGJ dibuka oleh Bapak Perbekel Desa Abiansemal sendiri.

\subsection{Pelatihan dalam Penanganan Orang Dengan Gangguan Jiwa (ODGJ)}

Penanganan ODGJ yang dilakukan masyarakat di Desa Abiansemal sampai saat ini masih berorientasi pada panti rehabilitasi masyarakat, puskesmas/rumah sakit umum dan sebagian masyarakat memilih melakukan pemasungan atau pembiaran terhadap masyarakat ODGJnya sendiri, sebagaimana banyak terjadi di wilayah-wilayah lain di Indonesia. Banyak masyarakat yang membiarkan ODGJ, mungkin hal tersebut juga yang menyebabkan ODGJ tidak mendapatkan penanganan khusus yang smestinya didapatkan oleh ODGJ. Penanganan ODGJ yang kompleks memang menjadi tantangan tersendiri bagi Pemerintah karena harus melibatkan banyak unsur, mulai dari Dinas Sosial, Dinas Kesehatan, Kepolisian, Babinsa dan masyarakat, sehingga sosialisasi sampai dengan pelaksanaan penanganan tidak dapat berdiri sendiri. Program penanggulangan ODGJ oleh masyarakat ini secara umum masih berkisar pada tatanan kuratif dengan koordinasi yang masih lemah dengan puskesmas sebagai penyedia fasilitas pelayanan dasar bagi kesehatan jiwa. Untuk itu dalam pengabdian kali ini, penyusun tidak hanya memberikan pendiidikan terkait ODGJ melainkan juga memberikan pelatihan bagi masyarakat dalam menangani ODGJ.Pembiaran yang dilakukan baik dilakukan oleh anggota keluarga dan juga masyarakat akan memberikan dampak ODGJ bebas berlalu lalang melakukan hal-hal yangdiinginkan. Padahal seharusnya. Pelatihan ini dilakukan untuk dapat mencegah tindakan-tindakan yang tidak diinginkan kepada ODGJ seperti pemasungan, pemukulan ataupun hal lainnya yang bersifat fisik sehingga memperburuk keadaan ODGJ. 


\subsection{Pendampingan keluarga Orang Dengan Gangguan Jiwa (ODGJ)}

Kurangnya pengetahuan keluarga tentang deteksi dini dan penanganan menyebabkan ODGJ tidak mendapatkan perawatan di rumah dengan optimal. Pemasungan dan pembiaran menjadi salah satu pilihan keluarga karena keluarga masih belum mampu atau bahkan tidak mempiliki kemampuan untuk menangani ODGJ baik secara materiil ataupun kesiapan mental keluarga sendiri. Padal sebagai orang terdekat dari ODGJ, keluarga menjadi sumber kekuatan ataupun moda penyembuhan ataupun penanaganan ODGJ.

Ketrepurukan penanganan ODGJ juga didukung oleh stigma terhadap orang dengan gangguan jiwa. Sehingga keluarga akan menolak apabila ada anggota keluarga yang diketahui memiliki gejala gangguan jiwa. Sehingga prognosis orang dengan gangguan jiwa akan semakin buruk sudah dianggap mengganggu serta membahayakan diri dan lingkungan sekitarnya maka akan dengan sangat terpaksa dilakukan pemasungan dan pembiaran.

Dalam pengabdiannya ini, kegiatan pengabdiannya tidak hanya difokuskan pada pendataan, pendidikan semata melainkan pendampinggan bagi keluarga ataupun asyarakat sekitar yang memiliki anggota keluarga ODGJ. Selain itu, pendampingan dilakukan agar pendidikan dan pelatihan yang telah dilakukan dapat diterapkan oleh masyarakat dan juga anggota keluarga yang memiliki ODGJ. Selain itu, pendampigan dilakukan karena pada saat pemberian pendidikan tentang ODGJ dan pelatihan penanganan, tidak semua kelurga yang memiliki ODGJ turut hadir dalam kegiatan tersebut.

\section{Kesimpulan}

Orang Dengan Gangguan Jiwa (ODGJ) merupakan bagian dari masyarakat yang seharusnya mendapatkan perhatian lebih baik dari keluarga, masyarakat bahkan pemerintah. Kegiatan pengabdian ini menjadi salah satu bentuk perhatian kepada kaum marjinal khususnya ODGJ sekaligus memberikan informasi bahwa ada kaum marjinal di lapisan masyarakat yang harusnya mendapatkan perhatian bukan malah pengucilan ataupun pelabelan stigma negative dari masyarakat. Pendidikan dan pelatihan dalam penanganan ODGJ serta pendampingan keluarga yang memiliki anggota keluarga ODGJ dalam pengabdian ini menjadi salah satu bentuk perhatian kepada ODGJ sendiri.

\section{References}

[1] Lestari, Weny dan Yurika Fauzia Wardhani. 2014. Stigma dan Penanganan Penderita Gangguan Jiwa Berat yang Dipasung. Surabaya : Buletin Penelitian Sistem Kesehatan - Vol. 17 No. 2 April 2014

[2] Idaiani, Sri dan Raflizar. 2015. Faktor Yang Paling Dominan terhadap Pemasungan Orang Dengan Gangguan Jiwa di Indonesia. Jakarta: Buletin Penelitian Sistem Kesehatan - Vol. 18 No. 1 Januari 2015: 11-17

[3] Pamungkas, Dwi Retno, One Way Linawati dan Puji Sutarjo. 2016. Stigma Terhadap Orang Dengan Gangguan Jiwa (ODGJ) Pada Mahasiswa Program Studi Ilmu Keperawatan Stikes Jenderal Achmad Yani Yogyakarta. Yogyakarta: Media Ilmu Kesehatan Vol 5, No 2.

[4] Laporan Riskesdas 2013

[5] http://nationalgeographic.grid.id/read/13946526/bali-peringkat-4-jumlah-penderita-gangguanjiwa-berat-di-indonesia?page=all diakses pada 15 Februari 2019 